\title{
Assessment of Seasonal Algae Variability in a Reservoir
}

\author{
Ju Young Lee ${ }^{1,2}$, Mooyoung Han $^{1^{\dagger}}$, Tschungil Kim ${ }^{1}$ \\ ${ }^{1}$ Department of Civil and Environmental Engineering, Seoul National University, Seoul 151-742, Korea \\ ${ }^{2}$ Center for Natural Products, Korea Institute of Science and Technology, Gangneung 250-377, Korea
}

\begin{abstract}
We investigated seasonal algae variability and its influence on water quality in an agricultural reservoir. We observed that maximal total phosphorus (TP) loads were $1,715 \mathrm{~kg}$ from farmland in September, which changed the ecosystem in the reservoir. At this time, Dictyosphaerium pulchellum as green algae dominated. Aulacoseira ambigua as diatom became the most dominant from November 2010 to May 2011. The diatom was sensitive to water temperature. Microcystis spp. and Oscillatoria spp. as cyanobacteria were dominant during summer and fall, and sank down to the sediment during winter and spring. Increasing water temperature during summer causes anaerobic conditions in the sediment, leading to regrowth of cyanobacteria. With regard to the ratio of total nitrogen $(\mathrm{TN})$ to TP, green algae and cyanobacteria were dominant at TN:TP ratios less than 20-30. Diatoms were dominant at TN:TP ratios greater than 30-40. Statistical analysis indicated that diatom growth was dependent on water temperature and TN concentration. TP concentration and water temperature were the key factors for the growth of cyanobacteria and green algae. From these results of this study, the management of land-use was an important parameter for improving water quality in the agricultural reservoir.
\end{abstract}

Keywords: Agricultural reservoir, Cyanobacteria, Diatom, Green algae, TN:TP ratio

\section{Introduction}

Phytoplankton is photosynthesizing microscopic organisms found in lakes, rivers, and oceans [1]. The most important groups of phytoplankton include diatoms, cyanobacteria and chlorophyta, although many other groups of algae are represented [1-3] Since the 1980s, many rural lakes have deteriorated because of eutrophication due to the inflow of phosphorus $(\mathrm{P})$, nitrogen $(\mathrm{N})$, and organic matter (C). These essential macronutrients are required for algal growth in lakes. Recent increases in heavy rainfall intensity, which cause an increase in the amount of $\mathrm{P}, \mathrm{N}$, and $\mathrm{C}$ in runoff entering streams or lakes, can increase algal growth, and water quality can deteriorate due to excessive $\mathrm{P}, \mathrm{N}$, and $\mathrm{C}$ levels, a phenomenon called 'eutrophication' [1, 4]. In recent times, many lake restoration projects and research papers that focus on water bodies with regard to difficulties in agricultural land-use management and the deterioration of water quality by eutrophication have concluded that excessive total phosphorus (TP) input load is a major factor [1, 3-6]. Input phosphorus is human-induced eutrophication, also called cultural eutrophication, and is largely a result of increased phosphorus inputs from sources, such as agricultural fertilizers or partially treated sewage [7, 8]. Therefore, lake management should not focus solely on the water body but also on the connection to the watershed. On the other hand, natural factors (i.e., lake morphology and geographic location) have not been of less concern [9-13]. Some studies suggest that the location of lakes (latitude and altitude) can significantly affect phytoplankton production/dynamics and water quality [9-11]. Lake morphology, such as lake depth and volume, is an important factor that reflects the capacity for nutrient inputs, which in turn affects eutrophication potential [13]. Climate variability, such as variations in precipitation and temperature, significantly affects water quality and phytoplankton production. Several studies demonstrate the forecasting of water quality based on relationships between climate parameters $[10,14,15]$. Thierfelder [16] and Nõges [11] have focused at the global level on the relationship between natural lake factors and water quality. The objective of this study was to investigate seasonal algal variability and its influence on water quality in an agricultural reservoir. Our approach was to identify key factors contributing to algal bloom of different types of phytoplankton (e.g., cyanobacteria, green algae and diatom) according to seasonal water physicochemical characteristics (e.g., total nitrogen [TN], TP, TN:TP ratio, and chemical oxygen demand [COD]). 


\section{Materials and Methods}

\subsection{Study Area}

The study site ('Mo-Jeon') was a reservoir with a total area of about $436,000 \mathrm{~m}^{2}$, located at $37^{\circ} 43^{\prime} 35.81^{\prime \prime} \mathrm{N}$ to $37^{\circ} 43^{\prime} 43.37^{\prime \prime}$ $\mathrm{N}$, and $128^{\circ} 53^{\prime} 17.59^{\prime \prime} \mathrm{E}$ to $128^{\circ} 53^{\prime} 46.02^{\prime \prime} \mathrm{E}$. The drainage area was $11,520,000 \mathrm{~m}^{2}$ and the maximum water capacity was 2,176 tons. The reservoir is located about $3.17 \mathrm{~km}$ south of Gangneung city in South Korea (Fig. 1), and serves as the major agricultural water source. Runoff from agricultural land, and wastewater from the combined sewage system in residential land, both flow into this reservoir. Streamflow was measured using a portable flow meter (propeller rotor assembly type, Model 3000). In particular, algal blooms were frequently observed during heavy rainfall in 2010 .

Land use in the area includes agricultural land (B, 65\%), residential areas (A, 17\%), forestland (C, 14\%), and roads/streams (D, 4\%). The maximum water level was 10-11 m near the embankment (St. 2) and the minimum water level was $1 \mathrm{~m}$ near the upstream edge (St. 1). The runoff from the agricultural and residential regions flows to the river. The reservoir was constructed in 1942. Table 1 shows the morphometric characteristics of the reservoir.

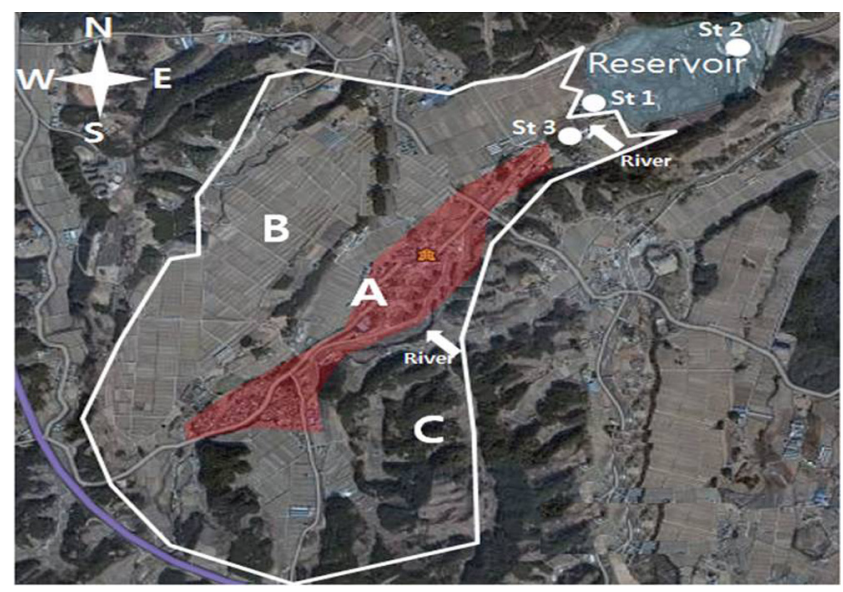

Fig. 1. Map showing land-use and sampling sites in a mo-jeon reservoir.

Table 1. Reservoir Morphometric Characteristics

\begin{tabular}{lc}
\hline \multicolumn{1}{c}{ Morphometric parameter } & Value \\
\hline Reservoir surface area $\left(\mathrm{m}^{2}\right)$ & 436,000 \\
Water capacity $\left(\mathrm{m}^{3)}\right.$ & 2,176 \\
Maximum water depth $(\mathrm{m})$ & 10 \\
Average water depth $(\mathrm{m})$ & 7 \\
Drainage area $\left(\mathrm{m}^{2}\right)$ & $11,520,000$ \\
Ratio of drainage area to reservoir area & 26.4 \\
Annual water inflow $\left(\mathrm{m}^{3}\right)$ & $7,105,900$ \\
Annual water outflow $\left(\mathrm{m}^{3}\right)$ & $7,230,200$ \\
Paddy and dry field area in drainage basin $\left(\mathrm{m}^{2}\right)$ & $7,488,000$ \\
Residential area in drainage basin $\left(\mathrm{m}^{2}\right)$ & $1,958,400$ \\
Forest and mountain area $\left(\mathrm{m}^{2}\right)$ & $1,612,800$ \\
Road and stream area $\left(\mathrm{m}^{2}\right)$ & 460,800 \\
\hline
\end{tabular}

\subsection{Field Sampling and Laboratory Methods}

Water and sediment samples were collected monthly and were analyzed for algal species distribution. Physicochemical parameters, such as $\mathrm{pH}$, dissolved oxygen, temperature, COD, TP, TN, chlorophyll-a (Chl-a), and Secchi depth (SD), were analyzed from 2010. In situ temperature, dissolved oxygen, and $\mathrm{pH}$ were measured using multi-parameter water quality equipment (YSI 620). Water samples were taken using a Van Dorn sampler. COD, TP, TN, and Chl-a were measured in the laboratory as prescribed in the standard method 19 edition [17]. SD was monitored using a Secchi disk (diameter $30 \mathrm{~cm}$ ). Phytoplankton qualitative samples were collected using a plankton net (Rhigosha NXXX25). Phytoplankton samples were preserved in Lugol's solution and counted under an inverted microscope [18].

\subsection{Data Analysis}

The lake trophic status index (LTSI) was used to make an estimate of lake or reservoir's biological condition. The LTSI was monthly calculated using the following equation [19]:

$$
L T S I=1.37 I N\left(1+\frac{C h l-\alpha \times T P}{S D}\right)
$$

where Chl-a and TP concentrations were expressed in $\mathrm{g} / \mathrm{L}$ and SD in $\mathrm{m}$. The LTSI used in this study was the average of LTSI (SD), LTSI (Chl-a), and LTSI (TP). Lake trophic categories were classified as oligotrophic, oligomesotrophic, mesotrophic, mesoeutrophic, and eutrophic conditions. The numerical range of the categories is (1) oligomesotrophic (2.3-2.6), (2) oligoeutrophic (2.7$3.0)$, (3) mesotrophic (3.01-4.2), (4) mesoeutrophic (4.21-5.4), (5) eutrophic (5.41-9.5), and (6) hypertrophic (>9.51).

\subsection{Statistical Analysis}

Descriptive statistics (i.e., box plot diagrams) were obtained using SPSS ver. $12 \mathrm{~K}$ software (SPSS Inc., Chicago, IL, USA). For correlation analysis, we performed a nonparametric Spearman rank correlation analysis to determine possible relationships among physicochemical parameters (e.g., TN, TP, TN:TP ratio, and water temperature) and phytoplankton (e.g., diatom, cyanobacteria, and green algae).

\section{Results and Discussion}

\subsection{Reservoir Water Characteristics}

Fig. 2 shows the change in water quality at different depths in the reservoir in 2010 . The temperature of surface water was $5^{\circ} \mathrm{C}-21^{\circ} \mathrm{C}$, and a thermal gradient was observed in the vertical profiles of TP, TN, COD, and Chl-a (depth 3-5 m) during the summer season. The cold dense water sinks to the bottom of lake and warm water is present at the surface in summer. It can be a thermal bar. Conversely, a cyclical pattern of overturn was observed on March 12 and December 13. The concentrations of TP, TN, COD, and Chl-a showed slight changes from the surface to the bottom. However, this is not likely to thermal stratification, but only a 

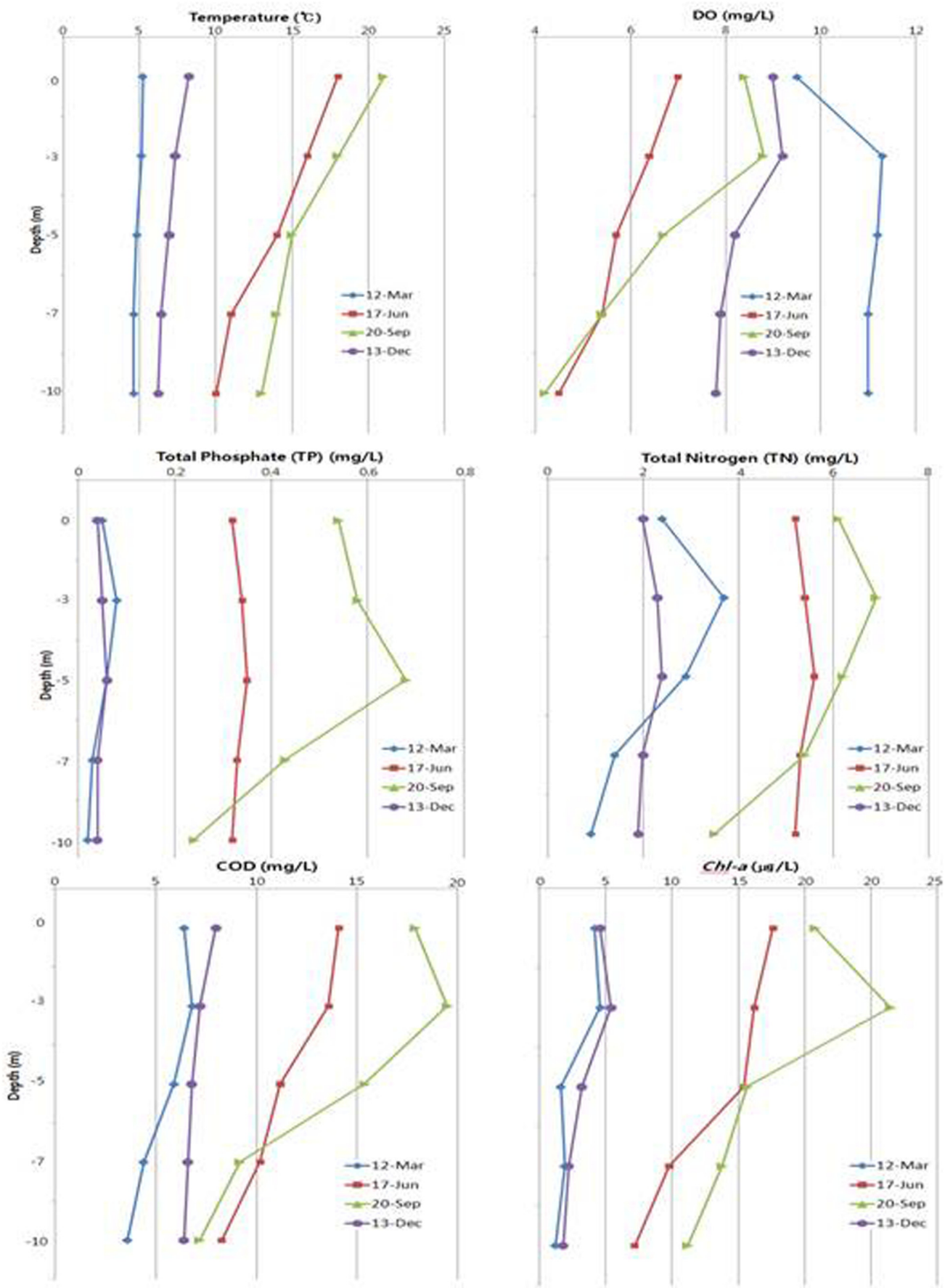

Fig. 2. Vertical profiles of limnological parameters at St. 2 in March 12, June 17, September 20, and December 13, 2010.

gradient between the bottom and the surface. Therefore, vertical distribution of nutrients is hardly to be related with thermal stratification.

Tables 2 and 3 show how TP, SD, and Chl-a levels were used to quantitatively evaluate the reservoir trophic level for eutrophication. LTSI values were 2.8 in March, 4.7 in June, 5.9 in September, and 2.5 in December. It should be noted that the reservoir condition was oligoeutrophic in March, mesoeutrophic in June, eutrophic in September, and oligomesotrophic in December. The highest LTSI value was in September and the lowest values were in December and March. This shows a close relationship with inflow TN and TP loads from the watershed to the reservoir (Table 4). Table 2 shows the highest monitored TP concentration as 0.64 $\mathrm{mg} / \mathrm{L}$ and the highest Chl-a as $28.7 \mu \mathrm{g} / \mathrm{L}$. In general, the average 
Table 2. Average Values of Physicochemical Parameters at the Surface in 2010

\begin{tabular}{cccccccccc}
\hline Month & WT $\left({ }^{\circ} \mathrm{C}\right)$ & $\mathrm{SD}(\mathrm{m})$ & $\mathrm{pH}$ & $\mathrm{DO}(\mathrm{mg} / \mathrm{L})$ & $\mathrm{COD}(\mathrm{mg} / \mathrm{L})$ & $\mathrm{TN}(\mathrm{mg} / \mathrm{L})$ & $\mathrm{TP}(\mathrm{mg} / \mathrm{L})$ & $\mathrm{N} / \mathrm{P}$ ratio & $\mathrm{Chl}-\mathrm{a}(\mu \mathrm{g} / \mathrm{L})$ \\
\hline Mar & 6.2 & 2.4 & 7.6 & 11.5 & 6 & 2.8 & 0.06 & 47 \\
Jun & 14.3 & 1.2 & 8.3 & 7.5 & 8.2 & 6.4 & 0.4 & 16 \\
Sep & 19.4 & 0.9 & 8.7 & 7.9 & 14 & 6.7 & 0.64 & 10 \\
Dec & 7.6 & 2.7 & 7.5 & 10.4 & 5.8 & 2.5 & 0.05 & 50 & 28.7 \\
\hline
\end{tabular}

WT: water temperature, SD: Secchi depth, DO: dissolved oxygen, COD: chemical oxygen demand, TN: total nitrogen, TP: total phosphorus, Chl-a: chlorophyll-a.

Table 3. Seasonal Change of LTSI Values and Categories at St. 2 in 2010

\begin{tabular}{ccc}
\hline Month & LTSI value & Reservoir trophic category \\
\hline Mar & 2.8 & Oligomesotrophic \\
Jun & 4.7 & Mesoeutrophic \\
Sep & 5.9 & Eutrophic \\
Dec & 2.5 & Oligomesotrophic \\
\hline
\end{tabular}

LTSI: lake trophic status index.

LTSI value of eutrophication in South Korea is more than 7.0. However, this reservoir did not exhibit such serious eutrophication as LTSI 5.9 .

\subsection{Phosphorus and Nitrogen Loading}

Table 4 shows the monthly concentration and load variation of $\mathrm{P}$ and $\mathrm{N}$ in the inflow at station 3. The monthly TN and TP show a close relationship with farming activity and the monsoon climate. In 2010, the rainy season continued for a month from June to August with rainstorms and heavy rainfall. Table 4 shows that the ranges of the monthly load were calculated as 7,984-21,498 $\mathrm{kg}$ TN and 603-1,247 kg TP and these were consistent with the rainy season from June to August in 2010. In particular, the highest monthly TP load calculated as $1,715 \mathrm{~kg} / \mathrm{mon}$ in spite of lower rainfall (13 days). The $\mathrm{P}$ and $\mathrm{N}$ loading can have a significant impact on the distribution of phytoplankton.

Table 4. Monthly Concentration and Load Variations of Phosphorus and Nitrogen at St. 3

\begin{tabular}{ccccccc}
\hline & & \multicolumn{2}{c}{$\begin{array}{c}\text { Average concentration } \\
\text { (2010) }\end{array}$} & \multicolumn{2}{c}{$\begin{array}{c}\text { Average load } \\
(2010)\end{array}$} \\
\cline { 3 - 4 } \cline { 6 - 7 } Month & $\begin{array}{c}\text { Rainfall } \\
\text { events }\end{array}$ & $\begin{array}{c}\text { TP } \\
(\mathrm{mg} / \mathrm{L})\end{array}$ & $\begin{array}{c}\text { TN } \\
(\mathrm{mg} / \mathrm{L})\end{array}$ & $\begin{array}{c}\text { TP load } \\
(\mathrm{kg} / \mathrm{mon})\end{array}$ & $\begin{array}{c}\mathrm{TN} \text { load } \\
(\mathrm{kg} / \mathrm{mon})\end{array}$ \\
\hline Jan & 8 & 0.25 & 3.44 & 13.9 & 190.7 \\
Feb & 8 & 0.37 & 4.38 & 56.7 & 671.0 \\
Mar & 13 & 0.48 & 5.95 & 97.6 & $1,209.8$ \\
Apr & 11 & 0.63 & 7.85 & 190.5 & $2,373.3$ \\
May & 12 & 0.67 & 6.49 & 242.3 & $2,347.4$ \\
Jun & 10 & 0.72 & 9.52 & 603.9 & $7,984.3$ \\
Jul & 18 & 0.45 & 5.6 & $1,153.4$ & $14,353.7$ \\
Aug & 24 & 0.94 & 16.2 & $1,247.4$ & $21,498.1$ \\
Sep & 13 & 1.78 & 20.7 & $1,715.0$ & $19,909.6$ \\
Oct & 5 & 0.67 & 8.3 & 105.3 & $1,305.0$ \\
Nov & 7 & 0.37 & 6.9 & 41.0 & 764.2 \\
Dec & 10 & 0.40 & 3.2 & 28.5 & 227.9 \\
\hline
\end{tabular}

TP: total phosphorus, TN: total nitrogen.

\subsection{Change in Dominant Phytoplankton Species}

Fig. 3 shows that the phytoplankton species exhibited a seasonal growth pattern. The diatom was the most dominant in winter and spring (November 2010 to May 2011). The maximum relative abundance of the diatom Aulacoseira ambigua was $72 \%$ in January 2010, compared to $67 \%$ in January 2011. In particular, the diatom and green algae were the dominant species in April 2010 and 2011. At this time, the average water temperatures were $7.7^{\circ} \mathrm{C}$ in 2010 and $6.5^{\circ} \mathrm{C}$ in 2011. As the temperature went up, the diatom abundance decreased to 7\% in September 2010 and 9\% in August 2011. This shows that diatoms are sensitive to water temperature. The abundance of green algae increased with increasing temperature. The maximum relative abundance of the green algae (Dictyosphaerium pulchellum) was 65\% in September 2010, compared to $45 \%$ in September 2011. In particular, the maximum relative abundance of green algae was related to TP load from the watershed. In Table 4, the highest TP load is seen to be $1,715 \mathrm{~kg} /$ September with an average temperature of $18.9^{\circ} \mathrm{C}$ in 2010 due to the high rainfall, while the TP load was $1,020 \mathrm{~kg} /$ September (not shown) with an average temperature of $20.1^{\circ} \mathrm{C}$ in 2011 . The growth of green algae was more sensitive to TP concentration than to water temperature. Cyanobacteria (Microcystis aeruginosa, Microcystis spp., and Oscillatoria spp.) were dominant in June 2010 (50\% abundance) and June 2011 (54\% abundance).

The abundance of cyanobacteria and diatoms had a seasonal pattern. The diatom became the dominant species, while the cyanobacteria sank down to the sediment from November to March. The increasing temperature leads to the regrowth of cyanobacteria during summer and fall season. The reason is that the increasing

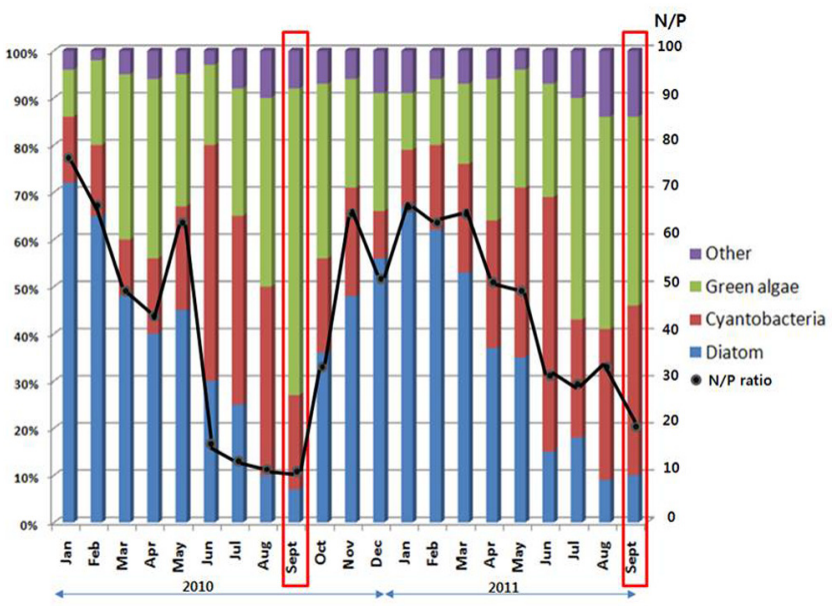

Fig 3. Relative abundance of dominant algae. N: nitrogen, P: phosphorus. 
Table 5. Correlation Coefficients ( $\rho$ ) of Phytoplankton Bloom with Physicochemical Parameters from 2010

\begin{tabular}{|c|c|c|c|c|c|c|c|c|c|}
\hline Parameter & WT & $\mathrm{TN}$ & $\mathrm{TP}$ & TN:TP & COD & DT & CB & GA & Other \\
\hline WT & 1.00 & 0.56 & $0.75^{* *}$ & $-0.80^{* *}$ & $0.82^{* *}$ & $-0.77^{* *}$ & $0.65^{*}$ & $0.69 *$ & $0.68 *$ \\
\hline $\mathrm{TN}$ & & 1.00 & $0.87^{* *}$ & $-0.75^{* *}$ & $0.75^{* *}$ & $-0.72^{* *}$ & 0.49 & $0.68^{* *}$ & 0.41 \\
\hline $\mathrm{TP}$ & & & 1.00 & -0.97 * * & $0.83^{* *}$ & $-0.86^{* *}$ & 0.65 & $0.73^{*}$ & 0.55 \\
\hline TN:TP & & & & 1.00 & $0.80^{* *}$ & $0.86^{* *}$ & -0.67 & $-0.69^{*}$ & $-0.61^{*}$ \\
\hline COD & & & & & 1.00 & $-0.74^{* *}$ & $0.78^{* *}$ & 0.63 & 0.39 \\
\hline $\mathrm{DT}$ & & & & & & 1.00 & $-0.69^{*}$ & $-0.67^{*}$ & -0.54 \\
\hline $\mathrm{CB}$ & & & & & & & 1.00 & 0.37 & 0.12 \\
\hline GA & & & & & & & & 1.00 & 0.64 \\
\hline Other & & & & & & & & & 1.00 \\
\hline
\end{tabular}

WT: water temperature, TN: total nitrogen, TP: total phosphorus, COD: chemical oxygen demand, DT: diatom, CB: cyanobacteria, GA: green algae.

water temperature causes anaerobic conditions in the sediment, and leading to the regrowth of cyanobacteria. The growth of phytoplankton appears to be closely associated with the TN:TP ratio. Green algae and cyanobacteria were dominant at TN:TP ratios less than 20-30. Diatoms were dominant at TN:TP ratios greater than $30-40$.

\subsection{Correlation Analysis}

Our statistical results suggest that the growth of phytoplankton is related to physicochemical parameters in 2010 (Table 5). Diatom growth was negatively correlated with $\mathrm{TN}(\rho=-0.72)$, TP $(\rho=-0.86)$, and COD ( $\rho=-0.74)$. The diatom dominated in winter and spring, based on statistical data (water temperature $\rho=-0.77$ ). Comparison of the correlation coefficient of TN:TP $(\rho=0.86)$ to the growth of cyanobacteria $(\rho=-0.67)$, green algae $(\rho=-0.69)$ and other phytoplankton $(\rho=-0.61)$ revealed that diatom growth was more

Table 6. Relative Abundance of Dominant Algae

\begin{tabular}{ccccc}
\hline Month & Diatom & Cyanobacteria & Green algae & Other \\
\hline Jan & 72 & 14 & 10 & 4 \\
Feb & 65 & 15 & 18 & 2 \\
Mar & 48 & 12 & 35 & 5 \\
Apr & 40 & 16 & 38 & 6 \\
May & 45 & 22 & 28 & 5 \\
Jun & 30 & 50 & 17 & 3 \\
Jul & 25 & 40 & 27 & 8 \\
Aug & 10 & 40 & 40 & 10 \\
Sep & 7 & 20 & 65 & 8 \\
Oct & 36 & 20 & 37 & 7 \\
Nov & 48 & 23 & 23 & 6 \\
Dec & 56 & 10 & 25 & 9 \\
Jan & 67 & 12 & 12 & 9 \\
Feb & 62 & 18 & 14 & 6 \\
Mar & 53 & 23 & 17 & 7 \\
Apr & 37 & 27 & 30 & 6 \\
May & 35 & 36 & 25 & 4 \\
Jun & 15 & 54 & 24 & 7 \\
Jul & 18 & 25 & 47 & 10 \\
Aug & 9 & 32 & 45 & 14 \\
Sep & 10 & 36 & 40 & 14 \\
\hline
\end{tabular}

dependent on TN concentration than on TP. On the other hand, the growth of cyanobacteria showed strong positive correlation with COD $(\rho=0.78)$, water temperature $(\rho=0.65)$, TN $(\rho=0.49)$, and TP $(\rho=0.65)$. The growth of green algae showed strong positive correlation with TP $(\rho=0.73)$, water temperature $(\rho=0.69)$, TN $(\rho=0.68)$, and COD $(\rho=0.63)$. In particular, TP concentration and temperature were the most important factors for the growth of green algae and cyanobacteria. To reduce deduction and be generalized, positive correlations based on monitoring sporadic data in 2009 and 2011 among cyanobacteria and green algae, TP, TN, water temperature, and COD were similar to result in Table 6 that not shown in this study.

\section{Conclusions}

In this paper, we investigated the seasonal algal variability and its influence on water quality in an agricultural reservoir. Our approach was to identify key factors for the algal bloom of different types of phytoplankton and their relationship to seasonal water physicochemical characteristics.

(1) With regard to the limnological aspect, the water quality changes at different depths $(3,5,7$, and $10 \mathrm{~m})$. Thermal stratification of temperature, TP, TN, COD, and Chl-a was observed during summer (e.g., September 20). A cyclical pattern of overturn was observed in the other seasons (March 12 and December 13) throughout the entire depth.

(2) Monthly TN and TP loads varied greatly seasonally. The monsoon climate and farming activity were the key factors affecting the nutrient load to the reservoir. In 2010, the highest monthly TP load was $1,715 \mathrm{~kg} /$ September at the inflow stream (St. 3) at the time of highest rainfall intensity. Most of the TN load flows into the reservoir by runoff from farmlands during the monsoon (June to September). Therefore, monthly TN and TP loads may be controlling factors determining phytoplankton growth.

(3) The growth patterns of different phytoplankton species showed seasonal patterns. The diatom (i.e., Aulacoseira ambigua) was the most dominant in winter and spring (November 2010 to May 2011). The diatom was more sensitive to water temperature. The maximum relative abundance of the green alga Dictyosphaerium pulchellum was $65 \%$ in 
September 2010 compared to $45 \%$ in September 2011. The maximum relative abundance of green algae was related to TP load from the watershed and was sensitive to TP concentration. Cyanobacteria (Microcystis aeruginosa, Microcystis spp., and Oscillatoria spp.) were dominant during summer and fall, and sank down to the sediment during winter and spring.

(4) Green algae and cyanobacteria dominated at TN:TP ratios less than 20-30, and diatoms were dominant at TN:TP ratios greater than 30-40 through monitoring data from 2010 to 2011. However, the published studies were rare and unidentified about the TN:TP ratios in relation to diatoms, green algae, and cyanobacteria. In fact, there is little hard generalization.

(5) Statistical analysis revealed that diatom growth was dependent on water temperature and TN concentration. On the other hand, cyanobacterial growth was showed strongly positive correlation to COD $(\rho=0.78)$, water temperature ( $\rho=$ $0.65)$, TN ( $\rho=0.49$ ), and TP ( $\rho=0.65)$. Further, the growth of green algae showed strong positive correlation with TP $(\rho=0.73)$, water temperature $(\rho=0.69)$, TN $(\rho=0.68)$, and COD $(\rho=0.63)$. Specifically, TP concentration and temperature were the most important factors determining the growth of green algae and cyanobacteria.

\section{Acknowledgments}

This research was supported by Korea Ministry of Environment (MOE) as Eco-Innovation Program (No.413-111-008).

\section{References}

1. Chen S, Chen X, Peng Y, Peng K. A mathematical model of the effect of nitrogen and phosphorus on the growth of blue-green algae population. Appl. Math. Model. 2009;33;1097-1106.

2. Correll DL. The role of phosphorus in the eutrophication of receiving waters: a review. J. Environ. Qual. 1998;27;261-266.

3. Li WC, Pan JZ, Chen KL. Studies and demonstration engineering on ecological restoration technique in the littoral zone of Lake Dianchi: the target and feasibility. Hu Po Ke Xue 2005;17;317321.

4. Paerl HW, Fulton RS, Moisander PH, Dyble J Harmful freshwater algal blooms, with an emphasis on cyanobacteria. Scientific World Journal 2001;1;76-113.

5. Chen W, Song L, Gan N, Li L. Sorption, degradation and mobility of microcystins in Chinese agriculture soils: Risk assessment for groundwater protection. Environ. Pollut. 2006;144:752-758.

6. Tu QY, Zhang YT, Yang XZ. Approaches to the ecological recovery engineering in Lake Shishahai, Beijing. $\mathrm{Hu}$ Po Ke Xue 2004;16;61-67.

7. Fraterrigo JM, Downing JA. The influence of land use on lake nutrients varies with watershed transport capacity. Ecosystems 2008;11;1021-1034.

8. Galbraith LM, Burns CW. Linking land-use, water body type and water quality in Southern New Zealand. Landsc. Ecol. 2007;22;231-241.

9. Brylinsky M, Mann KH. An analysis of factors governing productivity in lakes and reservoirs. Limnol. Oceanogr. 1973;18; 1-14.

10. Liu W, Zhang Q, Liu G. Lake eutrophication associated with geographic location, lake morphology and climate in China. Hydrobiologia 2010;644;289-299.

11. Nõges T. Relationships between morphometry, geographic location and water quality parameters of European lakes. Hydrobiologia 2009;633;33-43.

12. Nõges T, Nõges P, Laugaste R. Water level as the mediator between climate change and phytoplankton composition in a large shallow temperate lake. Hydrobiologia 2003;506-509; 257-263.

13. Taranu ZE, Gregory-Evans I. Quantifying relationships among phosphorus, agriculture, and lake depth at an inter-regional scale. Ecosystems 2008;11;715-725.

14. Fukushima T, Ozaki N, Kaminishi H, Harasawa H, Matsushige K. Forecasting the changes in lake water quality in response to climate changes, using past relationships between meteorological conditions and water quality. Hydrol. Process. 2000;14; 593-604.

15. Tibby J, Tiller D. Climate-water quality relationships in three Western Victorian (Australia) lakes 1984-2000. Hydrobiologia 2007;591;219-234.

16. Thierfelder T. The morphology of landscape elements as predictors of water quality in glacial/boreal lakes. J. Hydrol. 1998; 207;189-203.

17. Eaton AD, Clesceri LS, Greenberg AE. Standard methods for the examination of water and wastewater. 18th ed. Washington: American Public Health Association; 1995.

18. Utermöhl H. Zur vervollkommnung der quantitativen phytoplankton-methodik. Mitt. Internationale Ver. Theoretische und Angewandte Limnologie 1958;9:1-38.

19. Yang JR, Dickman M. Diatoms as indicators of lake trophic status in central Ontario, Canada. Diatom Res. 1993;8;179-193. 